\title{
Capacidade inovativa como estratégia de mudança de posicionamento estratégico: um estudo de caso de uma empresa do ramo da refrigeração médica científica
}

\author{
Clarice Vepo do Nascimento Welter* \\ Jorge Oneide Sausen *** \\ Gabriela Cappellari***
}

Resumo

Este estudo tem por objetivo identificar as tipologias de inovação, a partir do modelo de Wang e Ahmed (2004), desenvolvidas na Biotecno, empresa indústrial que atua no setor de refrigeração médica cientifica, situada em Santa Rosa-RS, no período compreendido entre 2001 a 2016, que determinaram em mudanças de posicionamento estratégico da empresa ao longo do período objeto de análise. Trata-se de estudo de caso único, de natureza exploratória e descritiva e de abordagem qualitativa. Os períodos de mudança estratégica foram analisados mediante as três dimensões da metodologia de Pettigrew, Ferlie e Mckee (1992), contexto, conteúdo e processo, fazendo uso do modo de análise longitudinal e histórico dos procedimentos da direct research (MINTZBERG, 1979). A partir dos dados coletados pode-se classificar a organização em três períodos estratégicos. Os resultados mostraram que no primeiro período a organização apresentou uma inovação de mercado, no segundo período inovação de produto ao nível radical e incremental, bem como inovação estratégica e comportamental e o terceiro período foi constituído novamente por inovação de produto. Em termos de contribuição para os estudos de capacidades inovativas, o presente trabalho considerou uma análise longitudinal dos processos inovativos na organização objeto de estudo. Embora a análise longitudinal tenha sido pautada pela investigação com base na memória dos agentes envolvidos, identifica-se uma tentativa de aprofundamento metodológico nesse campo de investigação.

Palavras chaves: Mudança estratégica, Capacidades dinâmicas, Inovação organizacional.

Administradora. Especialista em Gestão de negócios. Aluna do Programa de Pós-Graduação Strictu Sensu em Desenvolvimento - Universidade Regional do Noroeste do Estado do Rio Grande do sul (Unijuí). Email: clarice_vepo@hotmail.com

** Administrador. Professor do Programa de Pós-Graduação Strictu Sensu em Desenvolvimento - Universidade Regional do Noroeste do Estado do Rio Grande do sul (Unijuí). E-mail: josausen@unijui.edu.br

* Administradora. Especialista em marketing e gestão empresarial. Aluna do Programa de Pós-Graduação Strictu Sensu em Desenvolvimento - Universidade Regional do Noroeste do Estado do Rio Grande do sul (Unijuí). Professora substituta do Universidade Federal de Santa Maria (UFSM) Campus de Palmeira das missões. E-mail: gabriela.cplr@gmail.com

http://dx.doi.org/10.5335/rtee.v23i49.8258

Submissão: 04/03/2017. Aceite: 16/10/2017. 


\section{Introdução}

O dinamismo do mercado requer que as empresas adotem uma postura inovadora e de rápida adaptação ao ambiente, a fim de se manterem competitivas no mercado e a frente de seus concorrentes. Essa capacidade de inovação e de adaptação proporciona a organização obter uma vantagem competitiva garantindo assim seu espaço no mercado. Para que elas tenham essa habilidade de adaptar-se às mudanças ambientais e melhor se posicionarem no mercado, os empreendedores devem buscar estratégias empresariais para que consigam identificar as inovações que o mercado necessita e assim adequar-se às exigências desse mercado altamente dinâmico, inquieto e competitivo. Um desses modelos de estratégias competitivas é o das capacidades dinâmicas, tema que está ganhando grande importância nos últimos tempos.

As capacidades dinâmicas possuem importante papel na competitividade das empresas. Atingir um desempenho superior ou alcançar um melhor posicionamento competitivo em ambientes altamente mutáveis tem sido um tema amplamente tratado na literatura acerca da busca de diferenciais competitivos. A expansão do conceito de inovação e de tecnologia permitiu às organizações tornarem-se cada vez mais concorrentes, reconfigurando os recursos e capacidades existentes, visando à obtenção de vantagem competitiva (GUERRA; TONDOLO; CAMARGO, 2016).

Em busca de vantagem competitiva sustentável as organizações necessitam desenvolver suas capacidades inovativas que, conforme Wang e Ahmed (2007), é a habilidade da empresa em desenvolver novos produtos e mercados, mediante alinhamento estratégico para comportamentos e processos de inovação. Na ótica de Tigre (2006) as empresas mais dinâmicas e rentáveis do mundo são justamente aquelas mais inovadoras, que ao invés de competir em mercados saturados pela concorrência, criam seus próprios nichos e usufruem de monopólios temporários por meio de patentes e segredo industrial.

O processo de mudança e adaptação estratégica constitui-se em um dos principais diferenciais de empresas que estão inseridas em mercados cada vez mais competitivos. A mudança não é somente inevitável, mas necessária à sobrevivência das organizações (MOTTA, 1998). Nesse sentido, as mudanças estratégicas aparecem como consequências da análise e interpretação que os gestores fazem do ambiente, levando em conta a percepção e interpretação particular das condições objetivas do contexto que a empresa está inserida (DIVERIO; OLIVEIRA, 2006).

Considerando a busca das organizações pela sobrevivência diante um ambiente dinâmico e competitivo, o estudo partiu do seguinte problema de pesquisa: Como 
ocorreu o desenvolvimento de inovações em uma empresa industrial do ramo da refrigeração médica cientifica, no período de 2001 a 2016, que determinaram as mudanças de posicionamento estratégico da empresa?

O objetivo principal deste estudo foi identificar as tipologias de inovação, a partir do modelo de Wang e Ahmed (2004), desenvolvidas na Biotecno, empresa industrial que atua no setor de refrigeração médica cientifica, caracterizado pelo dinamismo em função das constantes alterações tecnológicas relacionadas ao avanço das pesquisas científicas no âmbito dos instrumentos e equipamentos de armazenagem e logística inerentes às especificidades deste segmento industrial.

Portanto, o estudo consistiu na análise das mudanças sob a ótica das capacidades de inovação ocorridas na empresa, do período compreendido entre 2001 a 2016, que determinaram em reposicionamentos estratégicos da empresa, localizada na região noroeste do Estado do Rio Grande do Sul, que ostenta a posição de ser empresa singular no ramo da fabricação de produtos de refrigeração médica científica nesta região.

Para tanto, foi necessário identificar e interpretar as fases de mudança estratégica da empresa estudada, com relação ao seu conteúdo (qual a mudança), seu contexto (o porquê da mudança) e seu processo (como se deu a mudança), de acordo com o modelo de análise de mudança organizacional proposto por Pettigrew, Ferlie e Mckee (1992), como também evidenciar o tipo de inovação desenvolvido pela empresa em cada uma de suas fases, de acordo com o modelo apresentado por Wang e Hamed (2004).

Realizar uma análise longitudinal que considere a evolução histórica dos tipos de inovações desenvolvidas pela empresa que ocasionaram as mudanças de posicionamento estratégico ao longo de sua trajetória, é oportuna, pois leva em consideração as causas e consequências de como essas mudanças ocorreram ao longo de sua história, permitindo uma melhor compreensão dos fatores e contingências que influenciaram as decisões tomadas.

O estudo do processo de adaptação estratégica sob a ótica das tipologias de inovações é relevante para contribuir com o entendimento de como as organizações desenvolvem suas inovações de produto, processo, mercado, comportamental e estratégica, principalmente numa perspectiva longitudinal, uma vez que os estudos presentes na literatura, referentes a esta temática, tem privilegiados análises seccionais.

A capacidade de inovação de uma organização permite a ela identificar novas oportunidades em mercados em expansão, aumentar as margens por meio de novas formas de fazer negócios e melhorar a eficácia operacional pela utilização mais 
eficiente e eficaz dos recursos existentes. Portanto, é necessário que as organizações sejam entidades criativas e capazes de transformar sua criatividade em inovações, para que consigam efetivamente incorporá-las nos seus produtos, processos, posições e paradigmas (TIDD; BESSANT; PAVITT, 2008).

Os resultados do estudo são apresentados em quatro partes, além desta introdução. Na primeira parte é apresentada as bases da abordagem das capacidades dinâmicas, que integra o enfoque da capacidade inovativa e os tipos de inovação, bem como o processo de mudança estratégica organizacional. Na sequência são apresentados os procedimentos metodológicos adotados na investigação empírica deste estudo. Posteriormente apresentam-se a discussão dos resultados e, por fim, as conclusões do estudo.

\section{Referencial teórico}

\subsection{Capacidades dinâmicas}

A teoria das capacidades dinâmicas constitui um ramo afluente nas atividades de pesquisa em administração. O pioneiro nos estudos sobre as capacidades dinâmicas foi Winter (1964), e desde a sua proposta original vários esforços têm sido dispensados com o intuído de desenvolver um conceito sobre este tema, especialmente do ponto de vista dos seus microfundamentos e operacionalização (ZOLLO; WINTER, 2003; WANG; AHMED, 2007; TEECE, 2009). Todavia foi somente a partir dos anos 90 que o termo capacidades dinâmicas foi aprofundado, mediante os estudos de Teece e Pisano (1994), Teece, Pisano e Schuen (1997) e posteriormente em Eisenhardt e Martin (2000).

O conceito de capacidades dinâmicas (TEECE; PISANO; SHUEN, 1997; EISENHARDT; MARTIN, 2000), é uma evolução da Visão Baseada em Recursos - VBR (WERNERFELT, 1984; BARNEY, 1991), respondendo as lacunas deixadas por essa teoria, como o fato dessa estratégia não ser suficiente para garantir uma vantagem competitiva sustentável. A RBV também não foi suficiente para explicar como algumas empresas respondem rapidamente às mudanças do ambiente externo, por meio da inovação de produtos, de forma flexível e com capacidades gerenciais que coordenam e reorganizam suas competências internas e externas. Por esse motivo o conceito de capacidades dinâmicas foi introduzido para propor respostas a esses gaps deixados pela RBV (TEECE; PISANO, 1994). 
O foco no processo de criação e alteração de recursos se alinha aos pressupostos da RBV, pois visa entender como os recursos são adquiridos, integrados, combinados ou ampliados para o desenvolvimento de uma capacidade que pode ser uma fonte de vantagem competitiva. As CDs possuem enfoque nas mudanças ocorridas nos recursos organizacionais. Nesse sentido, esta teoria possibilita às organizações responderem rapidamente às demandas do ambiente devido à sua capacidade de coordenar e reconfigurar suas competências (TEECE; PISANO, 1994).

Teece, Pisano e Shuen (1997) definem CDs como a habilidade da organização em integrar, construir e reconfigurar competências internas e externas para responder rapidamente aos ambientes em mutação. Eisenhardt e Martin (2000) asseveram que as CDs são os processos da firma que usam recursos para corresponder ou até mesmo criar mudanças de mercado. Esses autores asseguram que as capacidades dinâmicas são produtos da combinação de capacidades e rotinas simples relacionadas entre si.

Andreeva e Chaika (2006) associam capacidades dinâmicas às habilidades da organização em renovar suas competências chave conforme ocorrem mudanças no ambiente no qual a empresa opera. Na visão de Wang e Ahmed (2007), capacidades dinâmicas consiste no comportamento organizacional constantemente orientado a integrar, reconfigurar, renovar e recriar seus recursos e capacidades e, mais importante, melhorar e reconstruir suas capacidades chave em resposta às mutações do ambiente para atingir e sustentar a vantagem competitiva. Para estes autores as CDs é algo que está embutido nos processos.

Diante dos conceitos até aqui apresentados constata-se que capacidade dinâmica é a habilidade das organizações de identificar, implementar, reconfigurar e renovar a sua base de recursos. Recursos esses que podem ser tanto tangíveis como os intangíveis, bem como as suas competências, visando à obtenção de vantagem competitiva sustentável, garantindo assim uma posição segura no mercado. $\mathrm{O}$ desenvolvimento das CDs pode auxiliar as empresas contemporâneas a adquirirem vantagem competitiva, devido a capacidade da empresa em adaptar-se de forma antecipada a seus concorrentes, tendo em vista a configuração do mercado que se apresenta cada vez mais dinâmico e competitivo.

Wang e Ahmed (2007) apregoam que as capacidades dinâmicas são constituídas por três elementos componentes que juntos explicam os mecanismos utilizados pela empresa para relacionar a vantagem dos recursos internos com a vantagem competitiva baseada no mercado externo:

Capacidade adaptativa: é a habilidade da empresa em identificar e capitalizar as oportunidades emergentes de mercado. A capacidade adaptativa reforça a 
habilidade da organização em se adaptar no tempo certo por meio de flexibilidade e alinhamento dos recursos e suas capacidades com mudanças ambientais;

Capacidade absortiva: é a habilidade da empresa em reconhecer o valor de novas informações externas, de assimilá-las e aplicar isso para fins comerciais, sendo que a habilidade de avaliar e utilizar conhecimento externo ocorre largamente em função do nível anterior de conhecimento. Isso significa que a capacidade absortiva de uma organização é em função de sua trajetória ao longo do tempo. A capacidade absortiva realça a importância de obter conhecimento externo, combiná-lo com conhecimento interno e absorve-lo para uso interno da organização;

Capacidade inovativa: é a habilidade da empresa em desenvolver novos produtos e mercados por meio da orientação do alinhamento estratégico para comportamentos e processos de inovação. Para Wang e Hamed (2007), a empresa mais inovativa é aquela que possui maior capacidade dinâmica.

Neste estudo, pretendeu-se identificar as tipologias de inovação, a partir do modelo de Wang e Ahmed (2004), que determinaram em mudanças de posicionamento estratégico da empresa ao longo do período objeto de análise, fazendo uso de uma das dimensões das capacidades dinâmicas apregoadas por Wang e Ahmed (2007), a capacidade inovativa.

\subsubsection{O enfoque da capacidade inovativa}

Os estudos sobre inovação passaram a ter um maior espaço a partir da obra de Shumpeter, ("Teoria do desenvolvimento econômico", 1934), na qual o autor descreve a inovação como o ato de criar produtos ou serviços inovadores promovendo uma ruptura no sistema econômico, permitindo o surgimento de coisas novas. Nela o referido autor também apresenta o conceito de "destruição criativa" que é um processo de renovação constante e se constitui em uma força que mantém o capitalismo em movimento e impede que o mercado se conserve em uma posição de equilíbrio. Esse mesmo autor acrescenta que um dos motivos que permite à firma melhorar o desempenho por meio da inovação, consiste na possibilidade de se atingir uma posição de monopólio causada por patente ou devido ao tempo que as outras firmas demandam para copiar as ideias.

A inovação está ligada à capacidade de geração de ideias, implementando-as com o objetivo de obter sucesso (FONSECA, 2001). A capacidade inovativa vem sendo discutida desde a década de 1980 e ainda não possui consenso entre os pesquisadores na sua definição. Ela é definida como uma habilidade de moldar e gerenciar capacidades múltiplas, pois o esforço na busca pela inovação exige da empresa 
habilidades e competências para lidar com atividades diversas (CETINDAMAR; PHAAL; PROBERT, 2009). Wang e Ahmed (2007) definem capacidade inovativa como a habilidade da empresa em desenvolver novos produtos e mercados por meio da orientação do alinhamento estratégico para comportamentos e processos de inovação. Todavia, segundo a Pesquisa de Inovação (PINTEC), atividades inovativas são todas aquelas etapas científicas, tecnológicas, organizacionais e comerciais, incluindo investimento em novas formas de conhecimento, que visam à inovação de produtos e/ou de processos. Isto é, são todas as atividades necessárias para 0 desenvolvimento e implementação de produtos e processos novos ou aperfeiçoados. Estas atividades, de maneira geral, podem se desenvolver tanto dentro como fora da empresa.

Conforme assevera Barbieux (2011), os estudos feitos por Rush, Bessant e Hobday (2007) e Cetindamar, Phaal e Probert (2009), propuseram modelos de avaliação da capacidade inovativa como resultado do processo de aprendizagem tecnológica. Nesta abordagem ter capacidade inovativa significa adquirir informações, transformá-las em novos conhecimentos e obter novos produtos. Correio et al., (2013), baseado nos estudos de Silva, (2008) e Vieira, (2007) afirmam que a natureza estratégica da capacidade de inovar implica que, de um lado, os esforços para inovar são internos à empresa e, de outro lado, necessitam de informações de fontes externas. Assim, pode-se dizer que a capacidade inovativa é determinada, além da capacidade tecnológica, por um vasto número de fatores internos, externos e relacionais. Acrescentam, ainda, que Atoche (2007) trata da gestão de inovação não é satisfatória no que diz respeito à explicação da capacidade inovativa empresarial.

Para uma empresa ganhar competitividade mediante a inovação deve-se adaptar o processo de inovação as suas próprias possibilidade de desenvolvimento e integração de conhecimento e decidir sua própria capacidade de inovação (IBARRA; HERRERA, 2009). Empresas de sucesso são aquelas que conseguem gerenciar a coordenação e implementação de suas capacidades internas e externas, dando rápidas respostas ao mercado por meio da inovação de produtos (TEECE; PISANO; CHUEN, 1997).

A necessidade de inovação por parte das empresas deve ser constante a fim de que consigam atender as demandas do mercado. As empresas precisam desenvolver uma equipe criativa, que seja inovadora e que saiba trabalhar em equipe, com o intuito de renovar e reconfigurar seus recursos. Portanto, entende-se que capacidade de inovação é a capacidade de uma empresa em introduzir novos produtos no mercado, ou descobrir novos mercados para atuar, mediante a combinação estratégica com comportamentos e processos inovadores dos empreendedores e gestores. 


\subsubsection{Os tipos de inovação}

Segundo Tidd, Bessant e Pavitt (2008), a inovação pode assumir diversas formas, constituindo os 4Ps da inovação: Inovação de produto, inovação de processo, inovação de posição e inovação de paradigmas.

Segundo estes autores, a inovação de produto constitui-se nas mudanças nas coisas que uma empresa oferece, por exemplo, um novo modelo de carro, já a inovação de processo são as mudanças na forma em que os produtos ou serviços são criados e entregues, é a mudança nos métodos de fabricação ou nos equipamentos utilizados para produzir o carro. Já a inovação de posição são as mudanças no contexto em que os produtos/serviços são introduzidos, mudanças na forma como os produtos são introduzidos no mercado, incluindo o reposicionamento de um produto ou serviço já estabelecido em um contexto de uso especifico e a inovação em paradigma são as mudanças nos modelos mentais subjacentes que orientam as ações da empresa.

Com relação ao grau de novidade, a inovação distingue-se em inovação incremental e inovação radical. A inovação incremental refere-se a pequenas mudanças ocorridas nos produtos ou serviços, enquanto a inovação radical transforma o produto e a forma como pode ser utilizado (TIDD; BESSANT; PAVITT, 2008). Fonseca (2012), baseado nos estudos de Dantas (2001), menciona que a inovação radical é muito mais arriscada em relação à inovação incremental, no entanto, em caso de êxito terá um impacto muito superior no posicionamento competitivo da empresa, já que não será tão facilmente imitada pelos concorrentes.

Nesse sentido conforme o Manual de Oslo (OCDE, 2005), a inovação define-se pela implementação na empresa de algo novo ou significativamente melhorado e define quatro tipos de inovação: inovação de produto, inovação de processo, inovação de marketing e inovação organizacional. Segundo esta classificação:

- Inovação de produto: é a introdução de um bem ou serviço novo ou significativamente melhorado que concerne a suas características ou usos previstos;

- Inovação do processo: é a implementação de um método de produção ou distribuição novo ou significativamente melhorado;

- Inovação de marketing: é a implementação de um novo método de marketing com mudanças significativas na concepção do produto ou em sua embalagem, no posicionamento do produto, em sua promoção ou na fixação de preços; 
- Inovação organizacional: é a implementação de um novo método organizacional nas práticas de negócios da empresa, na organização do seu local de trabalho ou em suas relações externas.

No presente estudo, a capacidade de inovação terá como base o modelo teórico de Wang e Ahmed (2004), que inclui cinco dimensões: inovação de produto; inovação de processo; inovação de mercado; inovação comportamental; inovação estratégica.

Conforme esses autores a inovação de produto é fator determinante para o sucesso deste, assegurando a sustentabilidade econômica do negócio, pois a descoberta de produtos inovadores apresenta grandes oportunidades para as empresas em termos de crescimento e expansão, permitindo que as organizações atinjam uma posição confortável e dominante no mercado. Portanto inovação de produto é o ponto de partida, que pode consistir em pequenas modificações nos atributos do produto comercializado e até mesmo na inserção em tempo hábil desse no mercado, com a finalidade de atender o consumidor.

Já a inovação de processo, na visão destes autores, configura-se na introdução de novos métodos de produção, novas abordagens de gestão e novas tecnologias que poderão ser usadas para melhorar os processos da produção. Pode ser a introdução de uma nova matéria prima, ou novos equipamentos, ou uma melhora nos procedimentos.

A inovação de mercado refere-se à inovação condizente com a pesquisa de mercado, publicidade, identificação de novos mercados e entrada em novos segmentos. São as abordagens que as empresas adotam para entrar e explorar o mercado, identificando novos nichos para atuação.

A inovação comportamental pode ser observável em três níveis: ao nível individual, ao nível de uma equipe e ao nível da gestão. Essa inovação deve refletir a mudança comportamental sustentada diante a inovação. A inovação comportamental ao nível individual pode ser atribuída a indivíduos que sejam capazes de mudar de acordo com sua personalidade. A capacidade inovadora ao nível da equipe é a adaptabilidade da equipe à mudança. Por último, a capacidade inovadora ao nível da gestão reflete a disposição da gerência para a mudança e o seu compromisso para incentivar novas formas de fazer as tarefas, assim como a sua vontade de criar novas ideias.

Finalmente a inovação estratégica de acordo com esses autores é definida como sendo o desenvolvimento de novas estratégias competitivas que criam valor para a empresa, identificando novas oportunidades externas a fim de identificar uma lacuna existente entre os recursos internos e o ambiente externo. E a capacidade que a organização possui de repensar e muda estrategicamente seu negócio. 
Neste contexto, as inovações são capazes de gerar vantagens competitivas a médio e longo prazos. Inovar torna-se essencial para a sustentabilidade das empresas garantindo a elas vantagem em relação aos concorrentes e garantindo sua sobrevivência no mercado, pois diante do mercado altamente competitivo que vivenciamos, a inovação é fator determinante para a sobrevivência das organizações, de tal modo que a empresa que não se adequar corre o risco de ser descartada do mercado.

\subsection{Processo de mudança estratégica organizacional}

O desafio da mudança organizacional está inserido em um ambiente de incertezas e competição acirrada, ocasionado pelo dinamismo do mercado que exige das organizações a rápida percepção das mudanças que devem ocorrer de modo que possam permanecer nesse mercado cada vez mais competitivo. Pettigrew, Ferlie e Mckee (1992) descrevem que o processo de mudança diz respeito às ações, reações e interações das várias partes interessadas quando elas negociam em torno de propostas para a mudança. Ou seja, a mudança estratégica não deve ser apenas um evento visto de forma isolada, mas como um processo que envolve a visão de diversos atores envolvidos no processo, bem como uma avaliação das condições do ambiente e a escolha das novas estratégias.

A pesquisa sobre mudança deve envolver uma interação continua entre as ideias sobre o contexto, o processo e o conteúdo da mudança, junto com a habilidade de regular as relações entre os três (PETTIGREW; FERLIE; McKEE, 1992). A figura 1 ilustra essa abordagem.

Figura 1 - Modelo do processo de mudança

Conteúdo

Processo

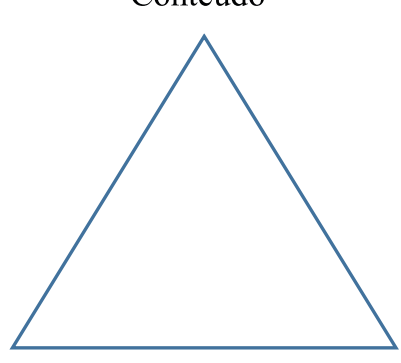

Contexto

(interno e externo)

Fonte: Pettigrew, Ferlie e Mckee (1992)

Teoria e Evidência Econômica - Ano 23, n. 49, p. 407-435, jul./dez. 2017 
O conteúdo condiz ao "o que" da mudança, refere-se à área de transformação em estudo e pode ser classificado de acordo com o conjunto de características mais abstratas, podendo afetar a adoção. Algumas mudanças são radicais e outras incrementais, algumas tecnológicas e outras de mudança nos papéis: a natureza da resposta organizacional pode ser moldada pelas características da questão que está sendo processada.

O contexto consiste no "por que" da mudança dividindo-se em contexto interno e externo. $\mathrm{O}$ contexto interno refere-se à estratégia, à estrutura, a cultura, ao gerenciamento e processo político atuais do distrito, ajudando a moldar os processos através dos quais as ideias para mudança procedem. $\mathrm{O}$ contexto externo refere-se ao contexto nacional econômico, político e social, bem como a percepção, ação e interpretação das políticas e eventos nos níveis nacionais/regionais, os movimentos sociais e profissionalização de longo prazo ou processos de desprofissionalização. O contexto delimita e restringe a ação.

O processo consiste no "como" da mudança, refere-se às ações, reações e interações das várias partes interessadas quando elas negociam em torno de propostas para mudança. Cada um dos stakeholders pode fornecer uma avaliação distinta do processo de mudança.

Pettigrew, Ferlie e Mckee (1992) afirmam que poucos estudos tratam o projeto de mudança como uma unidade de análise, geralmente focam em um conjunto de episódios ou fatos separados para dar forma a esse evento, significado e substância. Esses mesmos autores enfatizam que os estudos de mudança organizacional deveriam preocupar-se em fazer uma análise holística e dinâmica da mudança.

Desenvolver a percepção das mudanças do ambiente e ser capaz de elaborar estratégias que permitem a adaptação da organização às contingências do meio, são requisitos fundamentais dos gestores para promover processos de mudanças estratégicas nas organizações.

Gerenciar uma organização, nestes tempos, pressupõe gerenciar a mudança. Isto significa compreender e enfrentar as alterações rápidas e complexas do meio, confrontar-se com ambiguidades, compreender as necessidades de novos produtos, mercados e processos e, acima de tudo, garantir um sentido de direção em meio a um ambiente turbulento e dinâmico.

Em síntese, procurou-se, com essa breve fundamentação destes dois campos de estudos trabalhados ao longo dessa estrutura teórica, mostrar que o estudo das capacidades dinâmicas e, particularmente, da capacidade inovativa, constitui um segmento importante e uma vertente afluente nas atividades de pesquisa em gestão estratégica, mudanças organizacionais e busca de vantagens competitivas. 


\section{Metodologia}

Trata-se de uma pesquisa de âmbito exploratória e descritiva. Os estudos descritivos tem por objetivo primordial a descrição das características de determinadas populações ou fenômenos (GIL, 2002). Já os estudos exploratórios visam proporcionar maiores detalhes sobre determinado tema, cuja abordagem ainda carecem de explicações mais robustas do ponto de vista teórico. Neste sentido, a pesquisa exploratória busca maiores informações e é indicada quando se tem pouco conhecimento do assunto (MARTINS, 2000).

Trata-se, também, de um estudo de caso único e de abordagem qualitativa (TRIVIÑOS, 1987; YIN, 2004). Creswell (2010) considera que o estudo de caso é um método qualitativo com o qual o pesquisador explora em profundidade um programa, um evento, uma atividade, um processo ou um indivíduo. $\mathrm{O}$ caso único favorece uma compreensão mais robusta das circunstâncias em que os fenômenos ocorreram e, portanto, tendem a ser mais confiáveis.

Para orientar a investigação foram consideradas as dimensões propostas por Pettigrew, Ferlie e Mckee, (1992), de modo a analisar a mudança em termos do seu conteúdo (o que mudou), do contexto (porque mudou) e do processo (como mudou).

A técnica utilizada para coleta de dados foi a entrevista semiestruturada que é para a pesquisa qualitativa um dos principais meios que tem o investigador para realizar a coleta de dados, pois ao mesmo tempo em que valoriza a presença do investigador oferece todas as perspectivas possíveis para que o informante alcance a liberdade e a espontaneidade necessárias, enriquecendo a investigação (YIN, 2010).

Como método para a coleta e análise dos dados na presente pesquisa foram utilizados os procedimentos propostos pela direct research, apresentada por Mintzberg (1979), utilizando um modo longitudinal de análise com corte transversal, abordando a evolução da organização ao longo de um determinado período histórico, mas com foco em alguns momentos históricos chamados de incidentes críticos que marcaram a história do fenômeno. Foram realizadas as seguintes etapas conforme apregoa a direct research:

- Coleta de dados por meio de entrevistas semiestruturadas junto aos donos da empresa, o empreendedor e sua filha, que é gerente de qualidade e inovação e coleta de informações secundárias na página eletrônica da empresa e revistas;

- Identificação dos períodos históricos e estratégicos da empresa ao longo do período estudado; 
- Análise dos períodos estratégicos em que foi possível identificar as diferentes fases condizentes a mudança e adaptação estratégica da empresa visualizando as suas inovações e o grau de cada uma delas;

- Análise teórica dos períodos encontrados visando à explicação teórica das mudanças e estratégias encontradas.

\section{Apresentação e análise dos resultados}

A seguir está relacionado os eventos marcantes de cada período estratégico conforme descrito na metodologia do estudo, bem como a interpretação à luz da teoria da capacidade inovativa da organização, identificando os tipos de inovação conforme o modelo de Wang e Hamed (2004) relacionando com o grau de novidade, incremental ou radical. A sistematização das entrevistas realizadas e da análise documental resultou num conjunto de eventos críticos importantes que descrevem a trajetória da organização, desde a sua fundação, interpretada através de três períodos estratégicos (Quadro 1), produzidos a partir da análise das entrevistas.

Quadro 1 - Adaptação estratégica da Biotecno Indústria e Comércio Ltda (2001-2016) - Períodos estratégicos

\begin{tabular}{|c|c|c|}
\hline$N^{\circ}$ & Períodos de duração & Descrição \\
\hline I & $2001-2002$ & Identificação de oportunidade de negócio e fundação \\
II & $2003-2012$ & Reposicionamento de atuação no mercado \\
III & $2013-2016$ & Expansão de mercado \\
\hline
\end{tabular}

Fonte: Os autores.

\subsection{Período estratégico I - Identificação de oportunidade de negócio e fundação (2001-2002)}

Evento 1 - Fundação da empresa (2001)

A Biotecno é uma empresa com 15 anos de experiência no mercado de refrigeração médico-científica e em plena expansão. Foi fundada no ano de 2001 na cidade de Santa Rosa-RS, por Nerci Linck. O empreendedor identificou uma oportunidade no segmento de prestação de serviços de assistência técnica de aparelhos hospitalares, pelo fato de ter trabalhado durante 5 anos no setor de compras de um hospital da região e portanto conhecia os fornecedores e as dificuldades enfrentadas neste setor, dentre elas a falta de suporte técnico para hospitais. A motivação inicial era 
prestar serviços de assistência técnica e distribuição de produtos médicos por compra e venda.

O primeiro escritório da empresa foi na própria residência do empreendedor, pois na época ainda não recebia clientes. Neste período inicial, a equipe era composta pelo empreendedor e um funcionário, que hoje é coordenador de produção. Segundo a gerente de qualidade e inovação, que também é filha do empreendedor, neste período foi produzido diversos equipamentos além dos serviços de assistência técnica que a empresa prestava para os hospitais. Dentre os equipamentos produzidos tem-se: sofás, criado-mudo, cama, suporte de soro e foco cirúrgico. Porém como eram apenas o empreendedor e um funcionário a capacidade produtiva era limitada. Aos poucos surgiu a necessidade de contratar uma secretária e as funções foram sendo criadas conforme a necessidade.

Evento 2 - Aumento da demanda e mudança de local (2001)

Ainda no ano de 2001 ocorreu um aumento da demanda de prestação de serviço. Com essa nova perspectiva surgiu à necessidade de um espaço físico maior para a realização de consertos e produção de equipamentos. A partir desse momento a empresa iniciou sua migração para uma área industrial que primeiramente foi em prédio próprio.

Evento 3 - Incremento nos serviços prestados (2002)

Após a mudança de local foi agregado à prestação de serviços a venda de materiais, e com a formação de uma pequena equipe a empresa passou a produzir móveis hospitalares como: cadeiras de roda; focos cirúrgicos; estufas; e câmaras conservadoras. Em entrevista, a gerente de qualidade e inovação relembra que eles atendiam os hospitais de forma integral, realizando os serviços que fossem necessários, eram chamados a qualquer hora e isso exigia uma grande responsabilidade da parte deles, pois estavam trabalhando com vidas. Além da manutenção eram chamados para colocar rede de gás em todo o hospital, fabricar móveis hospitalares, suporte de soro e câmaras para conservação de sangue. A gerente comenta que esta característica de empreendedor, de atuar em diversos setores e aventurar-se no que até então era desconhecido permitiu know-how. O empreendedor, por meio de sua habilidade criativa buscava constantemente sua diferenciação no mercado, buscando oportunidades para manter a empresa atuante. 


\subsubsection{A estratégia inovativa do período}

O primeiro período estratégico foi marcado pelo comportamento empreendedor do fundador da empresa, em função da descoberta de uma nova oportunidade de negócio. Para Mintzberg, Ashlstrand e Lampel (2010) a escola empreendedora tem seu principal foco na visão que permite aos líderes empreendedores estarem sempre atentos às oportunidades oferecidas pelo mercado. A formulação de estratégias empreendedoras se caracteriza pela figura marcante do líder que gerencia a organização de forma autocrática, centralizando o poder e o controle, geralmente em uma estrutura organizacional simples (MINTZBERG; AHLSTRAND; LAMPEL, 2010). Ao surgir a oportunidade para a empresa realizar uma atividade diferente do seu negócio principal, no caso, a fabricação de móveis hospitalares, buscou atender este nicho de mercado, adaptando seu processo estratégico para atender a demanda do mercado existente. O empreendedor demonstra-se como calculista estando constantemente sintonizado com as mudanças ambientais que possam sugerir uma oportunidade favorável, passando rapidamente da identificação da oportunidade para sua perseguição (MINTZBERG; LAMPEL; AHLSTRAND, 2010).

Pelo fato deste período ser marcado pela identificação de oportunidade no segmento de manutenção hospitalar, foi caracterizado por uma inovação de mercado que conforme apregoa Wang e Hamed (2004) é a inovação relacionada com a pesquisa de mercado, publicidade e comunicação, bem como a identificação de novas oportunidades e entrada em novos segmentos. A inovação de mercado é bastante interligada com a inovação de produto e frequentemente foram estudadas como inovação de produto-mercado (WANG; AHMED, 2004).

\subsection{Período estratégico II - Reposicionamento de atuação no mercado (2003-2011)}

Evento 1 - Identificação de nova oportunidade de negócio (2003)

No ano de 2003 a empresa identificou uma nova oportunidade no mercado de refrigeração médico-científica. Os hospitais e distribuidores de vacinas eram penalizados com a falta de energia elétrica, ocasionada por vendavais, ou problemas da própria distribuidora de energia, o que ocasionava a perda de vacinas armazenadas em geladeiras domésticas ou no transporte feito em caixas de isopor com gelos. Para solucionar este problema a empresa deu início a fabricação de câmaras para

Teoria e Evidência Econômica - Ano 23, n. 49, p. 407-435, jul./dez. 2017 
conservação de vacinas e para sangue, um produto inovador e inédito no Brasil. Segundo a gerente, essa lacuna sempre existiu, sempre foi um problema a falta de energia elétrica, o que acarretava a perda de vacinas, pois as mesmas não podem ficar mais de 30 minutos fora da temperatura adequada. A recomendação da Agência Nacional de Vigilância Sanitária (Anvisa) é manter um freezer carregado com cápsulas de gelo reciclável e no momento da falta de energia comercial os mesmos devem ser alocados dentro da câmara de conservação, onde encontram-se as vacinas. Esta alternativa apresenta resultados satisfatórios, o problema é quando não há presença de funcionários na unidade de saúde, o que torna essa logística impossível de ser executada, principalmente quando ocorrem blecautes em função de tempestades ou durante horários não convencionais. A linha de câmaras para conservação de vacinas desenvolvidos pela empresa é capaz de manter-se em funcionamento em períodos de ausência de energia elétrica comercial, evitando onerosas perdas de material por estas eventualidades.

Evento 2 - Lançamento do No-break com o sistema de emergência para falta ou instabilidade de energia elétrica (2003)

Em 2003, ideia pioneira foi fabricar o No-break separado do produto. A empresa fabricava somente o No-break que poderia ser acoplado em qualquer equipamento. $\mathrm{O}$ empreendedor comentou que os hospitais compravam a peça como forma de segurança para eventuais problemas com a energia elétrica.

O ineditismo dos produtos da Biotecno está no desenvolvimento do sistema de emergência para falta ou instabilidade de energia elétrica, com autonomia variável entre 24 e 72 horas. A Biotecno foi idealizadora do sistema de emergência para falta de energia elétrica, até o ano de 2003 não existia esse tipo de equipamento no mercado, o que gerou uma certa desconfiança com relação a sua eficiência, "no começo ninguém acreditava no produto, achavam que não tinha como funcionar" comenta a gerente.

Evento 3 - Mudança de local e obtenção da autorização para funcionamento de empresa (2004)

Para poder fabricar as câmaras de refrigeração, a empresa necessitava de uma licença ambiental concedida pela ANVISA, a AFE, Autorização de Funcionamento de Empresa, essa autorização não foi concedida para o prédio da área industrial onde a empresa estava alocada, por consequência desse fato o empreendedor vendeu o pavilhão na área industrial e em 2004 migraram para um prédio alugado. Estando nesse novo prédio conseguiram a autorização de funcionamento. 
Nesse ano a empresa atendia boa parte dos hospitais da região e contavam com a colaboração de cinco funcionários.

Evento 4 - Lançamento da conservadora e No-break como acessório (2005)

Em 2005 foi desenvolvida a segunda ideia, fabricar a conservadora e vender o No-break como acessório. A estrutura era de uma geladeira doméstica, porém internamente era refeita toda a estrutura de refrigeração e vendiam os dois produtos separadamente.

Evento 5 - Exigência da Anvisa do registro do produto e certificação da empresa em boas práticas de fabricação (2008)

Outro evento importante neste período estratégico ocorreu em 2008, quando a ANVISA passou a exigir registro do produto e certificação da empresa em boas práticas de fabricação. Essas obrigações impostas pela ANVISA e com o crescimento do comércio de refrigeradores médicos representaram um desafio para a companhia, que passou a estabelecer procedimentos e a registrar todos os componentes dos equipamentos. A empresa teve que se adequar aos padrões e estruturar toda a planta e os processos para fabricar este tipo de equipamento. Esse processo se estendeu por mais dois anos.

Evento 6 - Lançamento das câmaras com No-breaks (2009)

No ano de 2009 teve início a implementação da terceira ideia, que consistia em acoplar o No-Break ao produto já com um sistema diferenciado de trabalho. As primeiras câmaras de conservação, com o No-Break já acoplado ofereciam autonomia elétrica de 12 horas. O lançamento das câmaras com No-Break impulsionaram os negócios da organização permitindo que a empresa investisse em melhorias em sua estrutura e contratasse mais funcionários. Após o lançamento deste equipamento a empresa passou a trabalhar com um produto totalmente inovador: um sistema de emergência com autonomia de 48 horas. Só não foi possível patenteá-lo porque foi considerado componente de um produto já existente. Atualmente a empresa oferece produtos capazes de armazenar medicamentos com até 72 horas de autonomia elétrica.

Evento 7: Tentativa de ingressar no mercado público de saúde (2011)

Em 2011 a empresa enfrentou outro evento crítico, a tentativa de ingressar no mercado público de saúde. A inexistência de empresas concorrentes em processos de licitações e a falta de enquadramento na modalidade de dispensa de licitação 
impossibilitou a empresa de prestar serviço para as instituições públicas, mas possibilitou uma nova perspectiva: a exploração do mercado privado.

Evento 8: Obtenção do registro na Anvisa e Certificado de Boas Práticas de Fabricação (2011)

Ainda em 2011 a empresa obteve o registro da sua linha de produtos na ANVISA e receberam o certificado de boas práticas de fabricação (BPF). A partir de então a empresa passou a produzir somente refrigeradores médicos e tornou-se especialista neste ramo de mercado, inclusive sendo hoje empresa referência em inovação neste segmento.

Evento 9: Definição do foco (2011)

Após a certificação da Anvisa, a empresa definiu o seu foco, delimitando seus serviços até então oferecidos para atender somente ao mercado de equipamentos de refrigeração para armazenamento de sangue, vacina etc. O empreendedor comentou que se eles não tivessem focado nas câmaras, hoje estariam do mesmo jeito que estavam em 2001, produzindo da mesma maneira, prestando assistência técnica aos hospitais, não teriam expandido tanto. Definir o foco foi fundamental para o crescimento da empresa.

Evento 10: Pirataria do produto (2012)

No ano de 2012, uma concorrente copiou o produto da empresa, no entanto acabou ajudando o empreendimento. $\mathrm{O}$ fato da entrada desse concorrente não foi suficiente para ameaçar os negócios da Biotecno, mas a partir da existência de outra fabricante, ela pode participar de licitações públicas. A empresa ganha os processos licitatórios, devido à qualidade de seus produtos e passa a vender para 0 setor público. "O concorrente alavancou nosso crescimento", afirma o empresário.

\subsubsection{A estratégia inovativa do período}

Com o lançamento do sistema de emergência para falta de energia elétrica, de uma só vez a empresa apresentava ao mercado uma grande novidade e aos seus clientes a solução de um grave problema que era a falta ou instabilidade da energia elétrica. Portanto, o segundo período estratégico foi marcado pela capacidade do empresário na identificação de novas oportunidades, e (re)organização de seus processos internos, gerenciais e tecnológicos, evidenciando assim a teoria das 
capacidades dinâmicas como vantagem competitiva deste período. As CDs possibilitam às organizações responder rapidamente às demandas do ambiente devido à sua capacidade de coordenar e reconfigurar suas competências (TEECE; PISANO, 1994).

A partir desse período começou a existir na empresa uma cultura para inovação, isso se configura como uma inovação comportamental, pois diz respeito ao compromisso que as pessoas da organização têm com a sustentação da inovação (WANG; AHMED, 2004). Se dando primeiramente ao nível individual, através do empreendedor, posteriormente a nível gerencial, e, por último, ao nível da equipe, onde todos os colaboradores engajaram-se na missão da empresa.

Este período é novamente marcado também pelo comportamento empreendedor do empresário de identificar oportunidade no mercado analisando o ambiente. O empreendedor está constantemente sintonizado às mudanças ambientais entendendo que o ambiente é algo maleável, podendo ser confrontado e controlado, apesar das forças externas (MINTZBERG; AHLSTRAND; LAMPEL, 2010)

Com relação ao tipo de inovação o terceiro evento configurou-se em uma inovação de produto. Conforme afirma Wang e Ahmed (2004), este tipo de inovação é fator determinante para o sucesso sustentável do negócio, pois a descoberta de produtos inovadores apresentam grandes oportunidades para as empresas em termos de crescimento e expansão do negócio, permitindo que as organizações atinjam uma posição confortável e dominante no mercado. No que tange ao grau de novidade constitui-se de uma inovação radical, pois não existia nada semelhante no mercado até o momento. Uma inovação radical transforma a forma como vemos as coisas (TIDD; BESSANT; PAVITT, 2008).

Com relação ao evento quatro, referente ao tipo de inovação continua sendo uma inovação de produto, porém quanto ao grau de novidade configura-se uma inovação incremental, pelo fato de aprimorarem um produto já existente. A inovação incremental refere-se a pequenas mudanças ocorridas nos produtos ou serviços (TIDD; BESSANT; PAVITT, 2008).

A partir das exigências da ANVISA, conforme relatado no evento 5, a empresa passou a adotar novos procedimentos para adequar-se às exigências deste órgão. A empresa adaptou-se de acordo com os fatores exógenos a organização.

No sexto evento, momento em que foi incorporado o No-Brake a conservadora, tornando um único produto, consistiu em uma inovação do produto inicial, porém quanto ao grau de inovação constitui-se em uma inovação incremental, pois foi uma melhoria no projeto feito anteriormente. 
O evento sete, momento em que a empresa tentou ingressar no mercado público de saúde houve então uma inovação estratégica, pois com a impossibilidade de participar de licitações por não haver concorrente, a empresa teve que repensar seu negócio e partir então para o mercado privado. Essa capacidade de repensar e modificar estrategicamente o negócio é característica da inovação estratégica. Esse tipo de inovação ocorre quando a organização identifica falhas de posicionamento na indústria e muda a sua forma de atuar com o objetivo de crescer e ser bem sucedida no mercado (WANG; AHMED, 2004).

Porter (1985) afirmava que para alcançar desempenho superior na indústria a empresa deve optar por uma das estratégias genéricas: liderança em custo, diferenciação ou foco. E foi a ação praticada pela empresa no evento nove, ela definiu o seu foco e começou a fabricar somente equipamentos de refrigeração para armazenamento de sangue, vacina etc. A estratégia baseia-se na condição de que a empresa é capaz de atender um segmento específico mais efetivamente e eficientemente do que os concorrentes que competem de forma mais ampla. Implica na possibilidade de aplicar uma abordagem de liderança de custo ou de diferenciação no segmento de mercado escolhido (PORTER, 1986).

Portanto, neste período, a empresa praticou estratégia inovativa de produto, estratégica e comportamental. As inovações de produto foram tanto ao nível radical, quando a empresa lançou a primeira ideia do produto, quanto ao nível incremental, onde a empresa aprimorou a ideia inicial do produto. A inovação comportamental se deu no momento que passou a existir na empresa uma cultura de inovação, onde todos os colaboradores foram encorajados a exporem suas ideias, visando a implementação de inovações que melhorassem o desempenho da empresa. E a inovação estratégica do período foi caracterizada pela necessidade da empresa de repensar o seu negócio, no momento que foi impossibilitada de ingressar no setor público, que era pensada como clientela prioritária, migrando para o setor privado.

\subsection{Período estratégico III - Expansão de mercado (2013 - 2016)}

Evento 1 - Desenvolvimento e lançamento da câmara de conservação portátil (2013)

No ano anterior teve início o projeto de desenvolvimento da câmara de conservação portátil - Modelo BT-1100/50, o primeiro modelo do equipamento de forma portátil com o intuito de desenvolver uma solução para o transporte de vacinas, 
sangue, amostras laboratoriais e órgãos. Com o objetivo de tornar o transporte de imunobiológicos, sangue, órgãos e medicamentos mais seguro e prático, a Biotecno desenvolveu um equipamento versátil e moderno, que funciona conectado à entrada auxiliar 12 volts do veículo (para transporte), na rede comercial e com uma bateria interna que o mantém em funcionamento por até 2 horas. Essa câmara desenvolvida pela empresa substitui as caixas isotérmicas e o gel de refrigeração.

Evento 2 - Lançamento da Câmara Portátil e patenteamento (2013)

No ano de 2013 esse produto foi lançado no mercado e teve sua patente encaminhada.

Evento 3 - Transição para empresa de médio porte (2014)

No ano de 2014 ocorreu a transição da empresa de pequena para médio porte e isso ocasionou um aumento relevante da carga tributária, e ao mesmo tempo que teve esse aumento de tributos, as vendas passaram a ser menos qualificadas. Com isso, a empresa está fazendo um esforço para manter sua lucratividade e para isso implementaram o orçamento base zero, reduzindo ao máximo os custos em todos os setores da organização.

Evento 4 - Alavancagem da linha veterinária (2014)

Neste mesmo ano a linha veterinária atingiu seu ápice, porque em 2012 o instituto mineiro de agropecuária aprovou uma lei mencionando que qualquer agropecuária, petshop ou clínica veterinária, deveria ter uma câmara para conservar as vacinas e não podia ser geladeira, se essa lei não fosse cumprida, o estabelecimento seria fechado. Então a empresa pegou a lei, a estudou e a partir daí criou três equipamentos simplificados, de tamanhos diferentes e com custo reduzido para atender esses clientes que achavam o equipamento com preço elevado, e em 2014 iniciou a comercialização. Após isso perceberam que não era viável fabricar um equipamento diferenciado para esse mercado e passaram a utilizar a mesma câmara da linha humana.

Evento 5 - Conquista da patente do produto (2016)

Em 2016 a empresa conquistou a patente da câmara de conservação e desde então a exclusividade de produção. Os equipamentos hoje são comercializados em todo o Brasil e a empresa está abrindo caminhos para a exportação. O produto, assim como a empresa, é registrado na Anvisa. Neste ano também houve o relançamento do modelo portátil da câmara de conservação. 


\subsubsection{A estratégia inovativa do período}

Este período foi marcado novamente por uma inovação de produto ao nível radical da empresa: a câmara portátil. Esta inovação trouxe grande eficiência para o mercado da saúde resolvendo um grande problema na conservação de vacinas, órgãos e amostras laboratoriais que careciam de transporte adequado. A empresa é a única desenvolvedora da câmara portátil no país. Assim como ocorreu no período estratégico II a empresa lançou um produto totalmente novo evidenciando mais uma vez o seu perfil inovador.

A partir dessa inovação radical a empresa teve um crescimento significativo, o que acarretou na sua transição de empresa pequena para médio porte. $\mathrm{O}$ desenvolvimento das inovações da empresa garantiram e ela conquistas de prêmios de inovação, como o Prêmio MPE Brasil, promovido pelo Sebrae nas categorias Indústria e Inovação e o $1^{\circ}$ prêmio ABIMED de inovação transformacional. $\mathrm{O}$ projeto da empresa "O transporte de vacinas saiu da era do gelo: um novo conceito para transporte e conservação de produtos" foi escolhido na categoria Melhoria do Padrão de Cuidados Médicos.

Esse período foi caracterizado por muitos aspectos relacionados ao modo empreendedor, como busca por novas oportunidades de mercado, pro atividade, foco no crescimento, que de acordo com Mintzberg (1973), são características normais de empresas com comportamento empreendedor. Quanto ao tipo de inovação do período caracterizou-se por uma inovação de produto ao nível radical.

Hoje a empresa encontra-se e um período de amadurecimento de sua estrutura e de organização das estratégias. A empresa está constantemente monitorando as mudanças que ocorrem no ambiente, buscando antecipar-se às tendências do mercado para que não seja pega desprevenida. Está sempre observando o mercado, com outros projetos em andamento visando à próxima inovação. Mais uma vez é destacado o perfil inovador da organização tendo no comportamento empreendedor de seu líder a principal fonte de ideias inovadoras e identificação de oportunidades.

O Quadro 2, a seguir, apresenta a sistematização dos períodos estratégicos de mudança, os eventos marcantes de cada período e a estratégia inovativa desenvolvida em cada um destes períodos pela empresa. 
Quadro 2 - Períodos estratégicos

\begin{tabular}{|c|c|c|c|}
\hline Período estratégico & Ano & Evento & Estratégia inovativa \\
\hline \multirow{2}{*}{$\begin{array}{l}\text { Período I: } 2001 \text { até } \\
2002 \\
\text { Identificação de } \\
\text { oportunidade de } \\
\text { negócio e fundação da } \\
\text { empresa }\end{array}$} & 2001 & $\begin{array}{l}1 \text { - Fundação da empresa } \\
2 \text { - Aumento da demanda e mudança de local }\end{array}$ & \multirow[b]{2}{*}{ Inovação de mercado } \\
\hline & 2002 & 3 - Incremento nos serviços prestados & \\
\hline \multirow{6}{*}{$\begin{array}{l}\text { Período II: } 2003 \text { até } \\
2012 \\
\text { Reposicionamento de } \\
\text { atuação no mercado }\end{array}$} & 2003 & $\begin{array}{l}1 \text { - Identificação de nova oportunidade de negócio } \\
2 \text { - Mudança de local e obtenção da autorização para } \\
\text { funcionamento de empresa (AFE) } \\
3 \text { - Lançamento do No-break com o sistema de emer- } \\
\text { gência para falta ou instabilidade de energia elé- } \\
\text { trica. }\end{array}$ & \multirow{6}{*}{$\begin{array}{l}\text { Inovação de produto } \\
\text { Inovação estratégica } \\
\text { Inovação } \\
\text { comportamental }\end{array}$} \\
\hline & 2005 & $\begin{array}{l}4 \text { - Lançamento da conservadora e no break como } \\
\text { acessório }\end{array}$ & \\
\hline & 2008 & $\begin{array}{l}5 \text { - Exigência da Anvisa quanto registro do produto } \\
\text { e certificação da empresa em boas práticas de } \\
\text { fabricação. }\end{array}$ & \\
\hline & 2009 & 6 - Lançamento das câmaras com no breaks & \\
\hline & 2011 & $\begin{array}{l}7 \text { - Tentativa de ingressar no mercado público de saú- } \\
\text { de } \\
8 \text { - Obtenção do registro na Anvisa e Certificado de } \\
\text { Boas Práticas de Fabricação. } \\
9 \text { - Definição do foco. }\end{array}$ & \\
\hline & 2012 & 10 - Pirataria produto & \\
\hline \multirow{3}{*}{$\begin{array}{l}\text { Período III: } 2013 \text { - } \\
2016 \\
\text { Expansão de mercado }\end{array}$} & 2013 & $\begin{array}{l}1 \text { - Desenvolvimento e Lançamento da Câmara de } \\
\text { Conservação Portátil; } \\
2 \text { - Lançamento do produto e patente encaminhada. }\end{array}$ & \multirow{3}{*}{ Inovação de produto } \\
\hline & 2014 & $\begin{array}{l}3 \text { - Transição para empresa de médio porte } \\
4 \text { - Alavancagem da linha veterinária }\end{array}$ & \\
\hline & 2016 & 5 - Conquista da patente do produto & \\
\hline
\end{tabular}

Fonte: Dados da pesquisa

O primeiro período (2001 a 2002) foi marcado por uma inovação de mercado, em que o empreendedor identificou oportunidades de negócio no segmento de prestação de serviços, na área de manutenção hospitalar. Logo em seguida, após atendendo as demandas desse mercado, entrou em um novo segmento, o de fabricação de móveis hospitalares. Pode-se dizer que, neste período, a empresa nasce sob a visão empreendedora de seu líder e as mudanças aconteceram a partir da visão do empreendedor em aproveitar as oportunidades do mercado, pela sua capacidade de fazer uma correta leitura do ambiente externo e implementar uma estratégia de inovação de mercado. 
O segundo período (2003 a 2012) da empresa foi marcado por inovações de produto, tanto ao nível radical quanto incremental, bem como inovação estratégica e comportamental. Novamente esse período foi marcado pela capacidade de percepção do empreendedor das oportunidades no mercado. Foi ele que identificou que existia o problema de falta ou instabilidade de energia elétrica, o que acarretava grande perda de vacinas e medicamentos e, após identificar essa lacuna, criou um produto totalmente inovador, que até então não existia no mercado, constituindo uma inovação de produto radical do período. A partir desta inovação radical, houveram inovações incrementais que aprimoraram a ideia inicial desse produto. A inovação comportamental foi identificada no momento que passou a existir uma cultura de inovação na empresa, com o compromisso de todos os envolvidos com a busca de inovações, visando o desenvolvimento e sobrevivência da empresa. A inovação estratégica ocorreu na medida em que a empresa foi forçada a repensar e modificar estrategicamente seu negócio, partindo para um foco no setor privado, uma vez que ela encontrou barreiras para ingressar no setor público.

O terceiro período estratégico (2013 a 2016) foi novamente marcado por uma inovação radical da empresa ao lançar no mercado outro produto totalmente inovador, revolucionando o mercado de transporte de vacinas, órgãos, sangue, etc. Novamente motivado pela visão apurada do empreendedor em observar as oportunidades no mercado e transformar essa visão em produtos para preencher as lacunas identificadas.

\section{Considerações finais}

Com o objetivo de compreender como e quais foram as mudanças estratégicas promovidas pela empresa estudada, à luz das capacidades inovativas implementadas no seu reposicionamento estratégico, constatou-se que a empresa concentrou seu foco de atuação, desde a sua fundação até os dias de hoje, em processos inovativos, de modo a buscar soluções para os problemas existentes no setor da indústria de refrigeração médica cientifica. Em todos os períodos estratégicos identificados a empresa apresentou algum dos tipos de inovação, daqueles caracterizados no modelo de Wang e Ahmed (2004), sendo que a inovação de produto foi a tipologia de inovação preponderante no período objeto de análise.

A cultura de inovação está muito presente na estrutura e dinâmica de funcionamento da empresa. A equipe de funcionários, de um modo geral, colabora com ideias, por meio de um mural exposto no refeitório da empresa, espaço provocador 
de sugestões para aprimorar processos, qualificar o ambiente ou até mesmo indicar novos rumos e perspectivas nos negócios da empresa. A inovação, nesta empresa, não é algo restrito a um único setor ou nível hierárquico da estrutura da empresa, é algo disseminado em todos os setores e áreas da organização.

A Biotecno é uma empresa inovadora, pois ela incorpora uma permanente reflexão da sua forma de atuação, dos seus instrumentos e processos de gestão e, sobretudo, dos desafios que se colocam no seu campo de atuação. Empresas como a Biotecno, que buscam soluções para problemas reais existentes, estão dispostas a corrigir caminhos e incorporar as mudanças que forem necessárias para um continuo aperfeiçoamento do seu fazer, das suas capacidades de dar respostas aos desafios e mudanças que o mercado lhe impõe.

Constatou-se no decorrer da análise dos períodos estratégicos de mudança, que a empresa assume uma postura prospectiva diante do ambiente de negócios. $\mathrm{O}$ comportamento empreendedor do seu gestor tem contribuído para a visualização das tendências de mercado e a rápida adequação na sua forma de agir. Fato que lhe tem proporcionado uma resposta positiva em termos de posicionamento competitivo no mercado.

Se uma empresa inovadora é aquela que introduz inovações de forma constante nos seus produtos, processos e mercados, é possível afirmar que a Biotecno é esse tipo de empresa, uma vez que ela obteve um crescimento significativo nos últimos anos, fruto da sua capacidade de adaptar-se ao ambiente, por meio da adoção de inovações e, principalmente, pela capacidade de percepção do seu gestor, que soube identificar nichos de negócios promissores no seu ramo de atuação.

Ao encerrar tal estudo percebe-se que o mesmo contribui como forma de análise, ainda que singular do objeto observado, mas com significações importantes a respeito do conhecimento sobre o tema capacidade inovativa e mudança organizacional, que ainda merece exploração no meio científico, sobretudo no campo dos estudos organizacionais, com abordagem de pesquisa longitudinal. Dentre os aspectos que podem ser considerados diferenciais neste estudo, está a perspectiva de observar a história de vida da organização, considerando os elementos de análise, a mudança estratégica por meio da capacidade inovativa, a partir de testemunhos orais e análise documental, que se confirmam como ferramentas eficazes para efetuar este tipo de estudo. 


\title{
Innovative capacity as a strategic positioning change strategy: a case study of a scientific medical refrigeration industry
}

\begin{abstract}
This study aims to identify the typologies of innovation, based on the model of Wang and Ahmed (2004), developed in Biotecno, an industrial company that operates in the scientific medical refrigeration sector, located in Santa Rosa-RS, in the period between 2001 to 2016, that determined in changes of strategic positioning of the company throughout the period under analysis. It is a unique case study, exploratory and descriptive in nature and qualitative approach. The periods of strategic change were analyzed using the three dimensions of the Pettigrew, Ferlie and Mckee (1992) methodology, context, content and process, making use of the mode of longitudinal and historical analysis of direct research procedures (Mintzberg, 1979). From the data collected, one can classify the organization into three strategic periods. The results showed that in the first period the organization presented a market innovation, in the second period product innovation at the radical and incremental level, as well as strategic and behavioral innovation and the third period was constituted again by product innovation. In terms of contribution to the studies of innovative capacities, the present work considered a longitudinal analysis of the innovative processes in the organization under study. Although the longitudinal analysis was based on research based on the memory of the agents involved, an attempt is made to deepen methodologically in this field of investigation.
\end{abstract}

Keywords: Strategic Change, Dynamic Capabilities, Organizational Innovation.

\section{Capacidad inóvativa como estrategia de cambio de posicionamiento estratégico: un estudio de caso de una empresa del ramo de la refrigeración médica científica}

\section{Resumen}

Este estudio tiene por objetivo identificar las tipologías de innovación, a partir del modelo de Wang y Ahmed (2004), desarrolladas en Biotecno, empresa industrial que actúa en el sector de refrigeración médica científica, situada en Santa Rosa-RS, en el período comprendido entre 2001 a 2016, que determinaron en cambios de posicionamiento estratégico de la empresa a lo largo del período objeto de análisis. Se trata de un estudio de caso único, de naturaleza exploratoria y descriptiva y de abordaje cualitativo. Los períodos de cambio estratégico fueron analizados mediante las tres dimensiones de la metodología de Pettigrew, Ferlie y Mckee (1992), contexto, contenido y proceso, haciendo uso del modo de análisis longitudinal e histórico de los procedimientos de direct research (MINTZBERG, 1979). A partir de los datos recolectados se puede clasificar la organización en tres períodos estratégicos. Los resultados mostraron que en el primer período la organización presentó una innovación de mercado, en el segundo período innovación de producto a nivel radical e incremental, así como innovación estratégica y conductual y el tercer período fue constituido nuevamente por innovación de producto. En términos de contribución a los estudios de capacidades innovadoras, el presente trabajo consideró un análisis longitudinal de los procesos innovadores en la organización objeto de estudio. Aunque el análisis longitudinal ha sido pautado por la investigación en base a la memoria de los agentes involucrados, se identifica un intento de profundización metodológica en ese campo de investigación.

Palabras clave: Cambio estratégico, Capacidades dinámicas, Innovación organizacional. 


\section{Referências}

ANDREEVA, T.; CHAIKA, V. Dynamic capabilities: what they need to be dynamic? St. Petersburg State University. São Petersburgo. 2006.

ATOCHE, C. Capability lifecycles: an insight from the innovation capability evolution in emerging economies. In: ANNUAL CLADEA CONFERENCE, 42, 2007, Miami. Anais... Miami: Florida International University, 2007.

BARBIEUX, D. Proposição de um modelo de análise de capacidade inovativa: das informações à mudança tecnológica. In: ENCONTRO ANUAL DA ANPAD, 35, 2011, Rio de Janeiro. Anais... Rio de Janeiro: Anpad, 2011.

BARNEY, J. B. Firm resources and sustained competitive advantage. Journal of Management, v. 17 , n. 1, p. 99-120, 1991.

CETINDAMAR, D.; PHAAL, R.; PROBERT, D. Understanding technology management as a dynamic capability: a framework for technology management activities. Technovation, v. 29, n. 4, p. 237-246, 2009.

CORREIO, M. R. W. et al. Capacidade inovativa: um estudo com empresas da indústria de vestuário do Ceará. Gestão Contemporânea, v. 10, n. 14, p. 91-118, 2013.

CRESWELL, J. W. Projeto de pesquisa: métodos qualitativo, quantitativo e misto. 3. ed., Porto Alegre: Artmed, 2010.

DANTAS, J. Gestão da inovação. Porto: Vida Económica, 2001.

EISENHARDT, K. M.; MARTIN, A. Dynamic capabilities: what are they? Strategic Management Journal, v. 21, n. 10-11, p. 1105-1121, 2000.

FONSECA, R. Inovação tecnológica e o papel do governo. Parcerias Estratégicas, v. 6, n. 13, p. 64-79, dez. 2001.

FONSECA, T. D.; O impacto das capacidades dinâmicas na inovação: uma comparação entre empresas vinícolas da Região do Alentejo e da Região de Provence. 2012. 131f. Dissertação (Mestrado em Negócios Internacionais) - Escola Superior de Tecnologia e Gestão do Instituto Politécnico de Leiria.

DIVERIO, T. S. M.; OLIVEIRA, L. C. P. Mudança estratégica organizacional: um estudo de caso na cooperativa castilhense. In: ENCONTRO NACIONAL DE ENGENHARIA DE PRODUÇÃO, 26, 2006, Fortaleza. Anais... Fortaleza-Ceará: Enegep, 2006.

GIL, A. C. Como elaborar projetos de pesquisa. 4. ed. São Paulo: Atlas, 2002.

GUERRA, R. M. A.; TONDOLO, V. A. G. O que (ainda) podemos aprender sobre capacidades dinâmicas Revista Ibero-Americana de Estratégia, v. 15, n. 1. p. 44-64, jan./mar. 2016.

IBARRA, E. R. B; HERRERA, L. Capacidad de innovación y configuración de recursos organizativos. Intangible Capital, v. 5, n. 3, p. 301-320, 2009.

IBGE. Instituto Brasileiro de Geografia e Estatística. Pesquisa Industrial de Inovação Tecnológica - Pintec. Rio de Janeiro: IBGE, 2014. Disponível em: <http://www.pintec.ibge.gov.br/downloads/manual_de_instrucoes_pintec_\%202014.pdf>. Acesso em: 12 fev. 2017. 
MARTINS, G. A. Manual para elaboração de monografias e dissertações. 2. ed. São Paulo: Atlas, 2000.

MINTZBERG, H.; AHLSTRAND, B.; LAMPEL, J. Safári de estratégia: um roteiro pela selva do planejamento estratégico. 2.ed. Porto Alegre: Bookman, 2010.

MINTZBERG, H. Strategy-making in three modes. California Management Review, v. 16, n. 2, p. 44-53, 1973.

. An emerging strategy of" direct" research. Administrative Science Quarterly, v. 24, n. 4, p. 582-589, 1979.

MOTTA, P. R. Transformação organizacional: a teoria e a prática de inovar. Rio de Janeiro: Qualitymark, 1998.

OCDE. Organização para a cooperação e desenvolvimento econômico. Mensuração das atividades cientificas e tecnológicas. Manual de Oslo. Diretrizes para a coleta e interpretação de dados sobre inovação. 3. ed. Rio de Janeiro, 1997. Disponível em: <http://www.finep.gov.br/images/ apoio-e-financiamento/manualoslo.pdf>. Acesso em: 29 out. 2016.

PETTIGREW, A.; FERLIE, E.; McKEE, L. Shaping Strategic Change. London: Sage Publications, 1992.

PORTER, M. Estratégia competitiva. São Paulo: Campus, 1985

PORTER, M. Estratégia competitiva: técnicas para a análise da indústria e da concorrência. 7. ed. Rio de Janeiro: Campus, 1986.

RUSH, H.; BESSANT, J. ROBDAY, M. Assessing the technological capabilities of firms: developing a policy tool. $R \& D$ Management, v. 37, n. 3, p. 221-236, 2007.

SCHUMPETER, J. The theory of economic development. Harvard University Press, Cambridge Massachusetts, 1934.

SILVA, M. J. Determinantes da capacidade inovadora empresarial ao nível da inovação no processo: modelo Logit. In: INTERNATIONAL CONFERENCE AEDEM, 17, 2008, Bahia. Anais... Bahia: Universidade Federal de Bahia, 2008.

TIDD, J.; BESSANT, J.; PAVITT, K. Gestão da inovação. 3. ed. Porto Alegre: Bookman. 2008.

TEECE, D.; PISANO, G. The dynamic capabilities of firms: an introduction. Industrial and Corporate Change, v. 3, n. 3, p. 537-556, 1994.

TEECE, D.; PISANO, G.; SHUEN, A. Dynamic capabilities and strategic management. Strategic Management Journal, v. 18, n. 7, p. 509-533, 1997.

TEECE, D. J. Dynamic capabilities \& strategic management. Oxford: Oxford University Press, 2009.

TIGRE, P. B. Gestão da inovação: a economia da tecnologia do Brasil. 7. ed. Rio de Janeiro: Elsevier, 2006.

TRIVIÑOS, A. N. S. Introdução à pesquisa em ciências sociais: a pesquisa qualitativa em educação. São Paulo: Atlas, 1987.

VIEIRA, F. Distritos industriais e inovação: o sector dos moldes em Portugal. $282 \mathrm{f}$. Tese (Doutorado em Engenharia de Produção de Sistemas) - Universidade do Minho - Escola de Engenharia, Portugal, 2007. 
ZOLLO, M.; WINTER, S. G. Deliberate learning and the evolution of dynamic capabilities. Organization Science, v. 13, n. 3, p. 339-351, 2002.

WANG, C. L. AHMED, P. K. The development and validation of the organisational innovativeness construct using confirmatory factor analysis. European Journal of Innovation Management, v. 7, n. 4, p. 303-313, 2004.

WANG, C. L.; AHMED, P. K. Dynamic capabilities: A review and research. International Journal of Management Reviews, Oxford, v. 9, n. 1, p. 31-51, 2007.

WERNERFELT, B. A resource-based view of the firm. Strategic Management Journal, v. 5, n. 2, p. 171-180, 1984.

WINTER, S. G. Economic 'Natural Selection' and the Theory of the Firm. Yale Economic Essays, v. 4 , n. 1 , p. 225-272, 1964.

WINTER, S. G. Understanding dynamic capabilities. Strategic Management Journal, v. 24, n. 10, p. 991- 995, 2003.

YIN, R. K. Estudo de caso: planejamento e métodos. 4. ed. Porto Alegre: Bookman, 2010. 